\title{
Game-Based Multimedia for Horizontal Numeracy Learning
}

\author{
$\underline{\text { https://doi.org/10.3991/ijet.v14i15.10679 }}$ \\ Dedi Rohendi \\ Universitas Pendidikan Indonesia, Bandung, Indonesia \\ dedir@upi .edu
}

\begin{abstract}
Recently, game-based multimedia development has been increasing rapidly. Game-based multimedia is not only used for entertaining but also for teaching and learning process. Meanwhile, for the majority of elementary school students, numeracy learning is still considered as a difficult subject to be learned and has not attracted students' interest because it still uses vertical methods. The objective of this research is to examine the implementation of game-based multimedia in learning horizontal numeracy. In this game-based multimedia, horizontal numeracy material is presented in the form of a game. Horizontal numeracy material begins with addition, subtraction, multiplication, and division. Game-based multimedia is implemented to 20 students in grade 3 elementary schools in Bandung, Indonesia. Subsequently, the way students learn the materials and their learning outcomes are explored after using this multimedia. The results show that the students can learn horizontal numeracy excitingly; moreover, they can easily understand the concept of horizontal numeracy quickly. It is indicated by the increasing of average post-test value.
\end{abstract}

Keywords - Horizontal numeracy, game-based multimedia, addition, subtraction, multiplication, and division

\section{Introduction}

In recent years, the use of multimedia has been widely used in the following fields: entertainment or games, promotion of business interests or advertisements, websites, and learning process. As an illustration, multimedia for learning English vocabulary [1], multimedia for measuring learning effectiveness [2], and multimedia for special education learning [3].

There are numerous advantages of using multimedia, including the availability of interactive properties and the ability to be read anywhere, anytime according to our needs. In addition, multimedia provides various features such as texts, graphics, images, sounds, videos, and animations [4], so that multimedia is very appropriate to be used as a medium or aid in learning processes because of the availability of all components that support learning processes [5]. However, the problem at the present time is that the use of media in learning processes is still very limited because of the inadequate ability of teachers to develop and use multimedia. 
Game-based multimedia is multimedia which its flow of presentation is designed corresponds to a game or the flow of multimedia running tailored to the game flow [6]. The types of the games used are varied, for example, arranging letters, numbers, or unique shapes to be certain forms just like a typical puzzle game; entertainment; and adventure games [7]. Everything is constructed as a way of attracting users to use multimedia. Moreover, by using game-based multimedia, students are expected to be interested to use multimedia while they learn a particular material displayed in the multimedia. This is in line with the opinion which states that one of the most important considerations to design teaching materials for young children is to stimulate their interests and to allow them to acquire knowledge in the process of playing games [1].

To date, learning to count in elementary schools in Indonesia is generally taught in a vertical mode to operate ones (units), tens, hundreds, and even thousands. Normally, students have not experienced difficulties in operating ones (units) in the vertical mode. However, when they operate tens, hundreds, and thousands with addition, subtraction, multiplication, and division in a vertical mode, many students commonly experience difficulties. One of the difficulties is to memorize a number that is more than ten which previously has been added up. The level of difficulty increases when the operating numbers are tens, hundreds, or thousands. By examining students' difficulties in learning the concept of mathematical operations in a vertical mode, it is revealed that students' numeracy skills are still low. When in fact, numeracy is so important to be mastered early by elementary school students because it is the basic concept of mathematics and is strongly emphasized in elementary school [9]. Based on these problems, innovative efforts are required in dealing with students' difficulties in learning to count. One thing that is tried to be implemented is counting by using a horizontal method. In addition, conventional learning of numeracy and the limited use of innovative media in learning to count in elementary schools in Indonesia are other factors that contribute to the students' low numeracy skills. Therefore, in this study, game-based multimedia will be implemented to students in learning to count. It is expected that students can quickly understand the concept of counting in addition, multiplication, subtraction, and division by applying them to a horizontal mode.

\section{$2 \quad$ Literature Review}

Educational media including game-based multimedia are tools which support learning processes. In addition to the methods and learning processes used by teachers, multimedia can also be used as a communication tool between students and teachers as well as between students and other students to create good learning processes [6]. Multimedia is also one of the important components in the learning processes likewise teachers and methods factors [7].

Game-based multimedia gives many advantages. Students can be entertained by playing games in the multimedia while at the same time learning the materials. Various game-based multimedia have been developed along with the development of information technology. Hence, multimedia has been widely used in schools and 
various levels of institutions for different purposes [10]. The use of multimedia with its advantages is indeed believed to be able to increase students' interest in learning [11].

Based on early observations and some of the existing data, a fact is obtained that the numeracy ability of elementary school students in Indonesia is still low, especially in the multiplication operation [2]. One thing that causes students to have low numeracy skills is the use of the vertical mode in counting. Therefore, in this study, the horizontal numeracy mode is applied within the game-based multimedia.

Horizontal numeracy is a new method and the completion of vertical arithmetic. According to [3], there are three reasons underlying the statement, i.e based on the process of addition, subtraction, multiplication, and division. First, the association concept of ones, tens, hundreds, thousands, and so on in the traditional method to complete the process of calculating addition or subtraction, but the emphasis is less because of the separation between the value of ones, tens, hundreds, and so on are not explicitly marked by a notation of the separator. While in the horizontal concept, the association's concept on the value is expressly separated with a notation of the fence. With the notations of the fence, the value of ones, tens, hundreds (|) (|| |) and so on will be more easily understood and imagined. First, an overview of metrics will be explained again. Metric is a method of calculating conducted horizontally by using the notation of the fence. Metric fence notation $\mid, \|, \ldots$ is the ' box ' containing the appropriate $1,2, \ldots$, numbers; if there is an excess it will be moved to 'the box' on the left and summed up; however if it is less, a zero will be added to 'the box' without changing the value.

Second, the process to calculate the multiplication through the horizontal numeracy turns out to be creating special patterns called as portals or horizontal patterns. Through the portal, the multiplication process becomes faster than the traditional one. For example, the square of the number 85 when conducted by using the horizontal method are as follows; $8 \times(8+1)\|25=72\| 25$, the result is seven thousand two hundred and twenty-five. Single digit multiplication with any number by using a common metric is very easy to be solved because there is no need for the brain to store the numbers. The necessary condition is only to master the multiplication 1 to 9 . For example: $3 \times 46=3 \times(4 \mid 6)=3 \times 4|3 \times 6=12| 18=13 \mid 8=138$

Two, three-digit multiplication via metric is the multiplication of two or three numbers, tens, hundreds of which are resolved by using the help of a gradual multiplication of one digit metric, until the final result is obtained, then drafted right align and resolved by using "Metris Menyerong (+M)".

Third, the horizontal arithmetic is good intermediary teaching; from learning basic numeracy into algebra. Algebra is a branch of mathematics by having signs and letters to illustrate or represent the numbers. By using the horizontal arithmetic, in particular, the completion of the multiplication using the portal, the students are led to know the value of a variable. This knowledge is a basic foundation of understanding an equation or function in algebra. 


\section{$3 \quad$ Methodology}

In this study, game-based multimedia is tested on 20 elementary school students in Bandung, Indonesia. Each student is required to use the multimedia from the beginning to the end of the learning process in the classroom. The teacher observes what students do to the multimedia. In the first part of the multimedia, students are required to do a pretest then follow the game step by step in the multimedia while studying horizontal numeracy materials. At the end of each material, an exercise is given to the students by answering some questions in the multimedia. Before the students end their exploration of the multimedia, a final test is provided which also must be answered by students.

The researcher recaps each student's score, both the pretest and the final test. Additionally, the researcher also observes what students have done in learning horizontal numeracy materials in game-based multimedia. The results of the initial and final tests are statistically processed to determine the increase in students' learning outcomes. The increase is calculated by using N-Gain.

$$
N \text {-Gain }=\frac{\text { posttes-prestest }}{\text { actual score-pretest }}
$$

The criteria for determining the amount of the increase are as follows:

Table 1. N-Gain Criteria

\begin{tabular}{|c|l|}
\hline \multicolumn{1}{|c|}{$\mathbf{N}-$ Gain } & \multicolumn{1}{|c|}{ Criteria } \\
\hline $0,00<=\mathrm{N}-$ Gain $<0,40$ & Low \\
\hline $0,40<=\mathrm{N}-$ Gain $<0,60$ & Middle \\
\hline $0,60<=\mathrm{N}-$ Gain $<0,80$ & High \\
\hline $0,80<=\mathrm{N}-$ Gain $<1,00$ & Very High \\
\hline
\end{tabular}

\section{$4 \quad$ Result and Discussion}

Game-based multimedia that has been developed begins with the pretest. In this section, students are required to answer all numeracy questions in the form of multiple choices from the first to the last question. After the students answer all the questions (Figure 1a), the scores obtained by the students are displayed in the last part of the multimedia (Figure 1b). The pretest is intended to determine students' initial numeracy skills before learning the horizontal numeracy materials from the multimedia. 


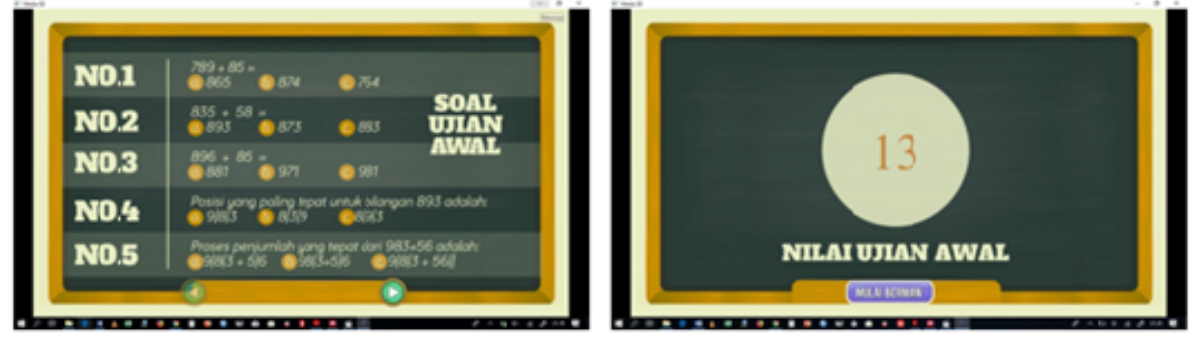

Fig. 1. 1a. Pretest questions 1b. The final score of the pretest

After that, students are directed to play the game which is started by logging in using a registered account. Then, the multimedia presents the rules and the instructions from the beginning to the end of the game. The game in multimedia involves a diamond collecting adventure to obtain a collection point. At the end of each level, there is a book which is required to be collected by the user. The book then opens and displays some numeracy materials. As shown in Figure 2a and Figure 2b.

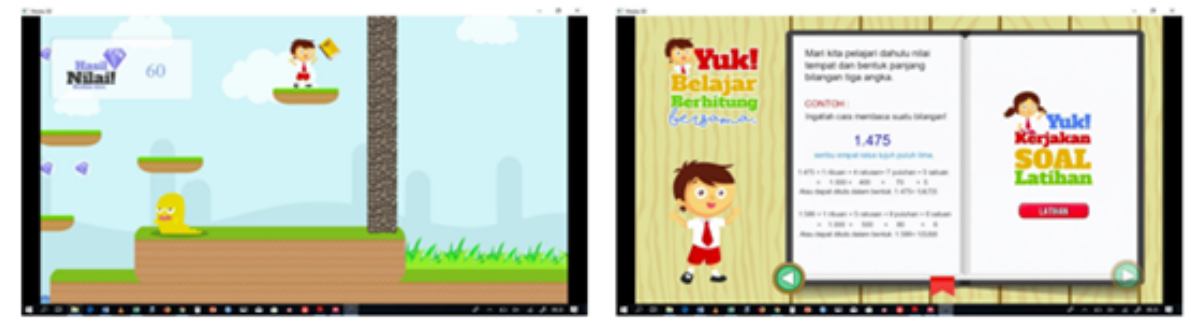

Fig. 2. 2a. Level 1 of the game 2b. First material: Introduction to number

Figure 2a shows that students have completed the last section of the game. Afterward, students are required to click on the picture of the book. If the book is clicked, the first material about number position which includes the position of ones, tens, hundreds, and thousands. Figure $2 \mathrm{~b}$ displays that students study the materials. In this material, students are shown the position of the numbers, for example, for number 1475 , number 1 , indicates thousands, number 4 , indicates hundreds, number 7 , indicates tens and number 5 , indicates ones (units). So: $1475=1$ thousand +4 hundreds + 7 tens +5 ones.

By showing the position of the number, it is expected that the third-grade students, who have just learned about thousands, understand each number position according to its value. Then, at the end of the material delivery, an exercise is given. The exercise is shown in Figure 3a and Figure 3b. 

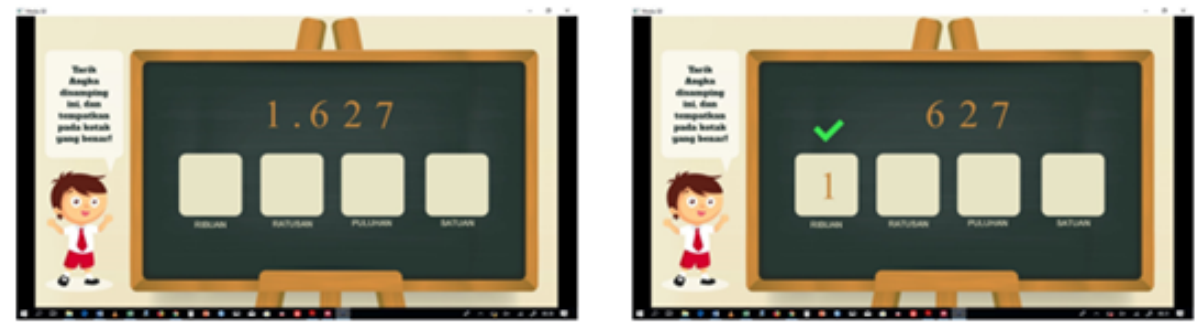

Fig. 3. 3a. Question of the exercise 3b. Example of drag and drop result

In Figure 3a, students are asked to drag and drop the number 1627 and move it to the available boxes. As in Figure 3b, students drag number 1 in the first box. If it is correct, a checklist $(\sqrt{ })$ will appear above the available box. By playing this game, it is expected that students' understandings about the position of the numbers will increase and they are able to put the numbers $1,6,2$, and 7 in the correct places respectively. The questions provided in the multimedia are plenty and all of them have to be solved by the students. If the students answer all the questions correctly, then the multimedia will display the rank of the student in a game as it is shown in Figure 4.

By displaying the rank of students, students are expected to gain motivation to use game-based multimedia, because of its fun principles.

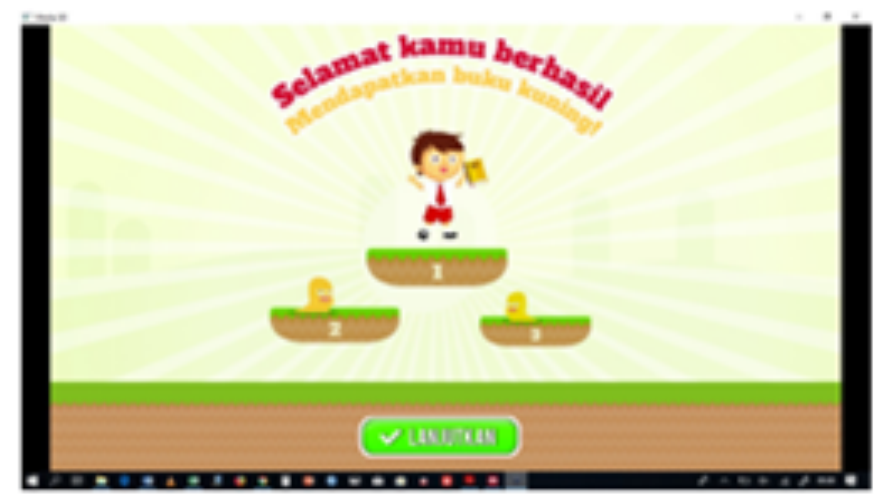

Fig. 4. Students answer all questions correctly

By looking at these examples, it is hoped that students' understanding of the position of numbers is improving. This concept is the initial concept of further materials which are addition, subtraction, or multiplication, and division in the horizontal mode. After passing the first level, students are directed to the next level. Similar to the beginning of the game, students are asked to continue playing in level 2 which is a little more difficult than level 1. At each level, students not only have to obtain points from collecting diamonds but also have to face a monster that will disrupt them throughout the game. Thus, students must try to avoid the monster to prevent the game from stopping and restarting from the beginning. Another way to stop the monster that can 
be performed by the students is throwing some bullets by clicking the space button on the keyboard. At the end of level 2, similar to level 1, students also have to choose a picture of a book and the multimedia will display the next materials. This process continues at every level. At this level, the multimedia will lead students to learn about addition as shown in Figure 5.

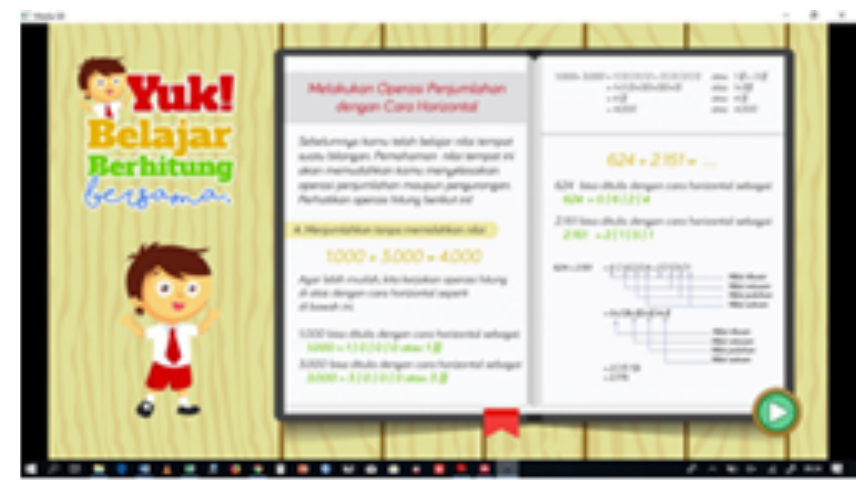

Fig. 5. Addition in numbers

Figure 5 presents the material about addition in the multimedia using the horizontal method. In this example, it is shown the way to add numbers $624+2151$.

$624=0|6| 2 \mid 4$

$2151=2|1| 5 \mid 1$, so, the process of addition by using the horizontal method is as follows:

$624+2151=0|6| 2|4+2| 1|5| 1$

$=0+2|6+1| 2+5 \mid 4+1$

$=2|7| 7 \mid 5$

$=2775$

The course of the game on the multimedia continues until the final material about division is delivered. Students also continue to play the game by collecting points from the collected diamonds. At the end of the multimedia, a posttest is given. The questions of the posttest are not much different from the pretest questions. The difference is that when doing the pretest, the students have not acquired the materials about adding, subtracting, multiplying, and distributing numbers in horizontal mode, whereas when they are doing the posttest, the students have been given the materials in stages through the game they are playing. To attain the score of the pretest and posttest, the researcher recaps all the scores by checking them from each computer used by the students. This step is conducted because the multimedia is not connected to a system (online) and does not provide a database so students' scores are not recorded in the computer.

The results of the pre-test and post-test of 20 students are presented in Table 2 as follows. 
Table 2. Pretest and posttest results

\begin{tabular}{|l|c|c|c|c|c|c|c|c|c|c|c|c|c|c|c|c|c|c|c|c|}
\hline Students & S1 & S2 & S3 & S4 & S5 & S6 & S7 & S8 & S9 & S10 & S11 & S12 & S13 & S14 & S15 & S16 & S17 & S18 & S19 & S20 \\
\hline Pre test & 66 & 46 & 64 & 80 & 80 & 46 & 46 & 46 & 80 & 66 & 46 & 66 & 80 & 40 & 80 & 80 & 46 & 46 & 46 & 40 \\
\hline Post Test & 80 & 80 & 80 & 80 & 85 & 73 & 85 & 73 & 85 & 73 & 80 & 73 & 80 & 80 & 90 & 80 & 73 & 85 & 73 & 80 \\
\hline
\end{tabular}

Based on Table 2, it can be explained that the score of the pretest ranges from 40 as the minimum score and 80 as the maximum score. Meanwhile, the minimum score of the posttest is 73 and the maximum score is 90 . Additionally, there is an increase in the average pretest score which is 58 to the average posttest score which is 79 . Therefore, by looking at the escalation of the average scores, the use of game-based multimedia can increase students' abilities to count by using the horizontal mode.

Table 3. N-Gain results

\begin{tabular}{|l|c|c|c|c|c|c|c|c|c|c|c|c|c|c|c|c|c|c|c|c|c|}
\hline Students & S1 & S2 & S3 & S4 & S5 & S6 & S7 & S8 & S9 & S10 & S11 & S12 & S13 & S14 & S15 & S16 & S17 & S18 & S19 & S20 & Sum \\
\hline Pre test & 14 & 34 & 40 & 0 & 5 & 27 & 39 & 27 & 5 & 7 & 34 & 7 & 0 & 40 & 10 & 0 & 27 & 39 & 27 & 40 & 422 \\
\hline Post Test & 34 & 54 & 60 & 20 & 20 & 54 & 54 & 54 & 20 & 34 & 54 & 34 & 20 & 60 & 20 & 20 & 54 & 54 & 54 & 60 & 834 \\
\hline
\end{tabular}

The data in Table 3, shows that the N-Gain score is 0.51 . This score indicates that there is middle increase in the ability of students to understand the numeracy concept by using the horizontal method. This means that the numeracy ability of students after learning numeracy in the horizontal method using game-based multimedia is averagely better than before. This result shows that learning numeracy using game-based multimedia significantly contributes to the improvement of students' numeracy skills. During the learning processes, students are enthusiastic to learn about numeracy, as shown in Figures $6 \mathrm{a}$ and $6 \mathrm{~b}$ because they are supplemented by an adventure game (collecting points from the diamonds). Hence, the game provides positive motivation for students to learn certain materials [14].

In Figures $6 a$ and $6 b$, it can be seen that the students are immersed in numeracy learning particularly the application of horizontal method using their respective laptops. They carefully and enthusiastically open page after page of the multimedia to collect points through gathering the diamonds in the game. In addition, because interactive exercise is provided in this multimedia, the students also try to answer all the practice questions carefully. They drag and drop the answers of the questions, either by putting the number in the correct position or matching the number with its pair. These practice questions are also designed like common games that the students usually play so while they are playing the game, they are also learning the concept of numeracy in a horizontal method. Hence, multimedia can be considered to be a relatively effective method which can increase the quality of learning processes in the classroom [15]. 

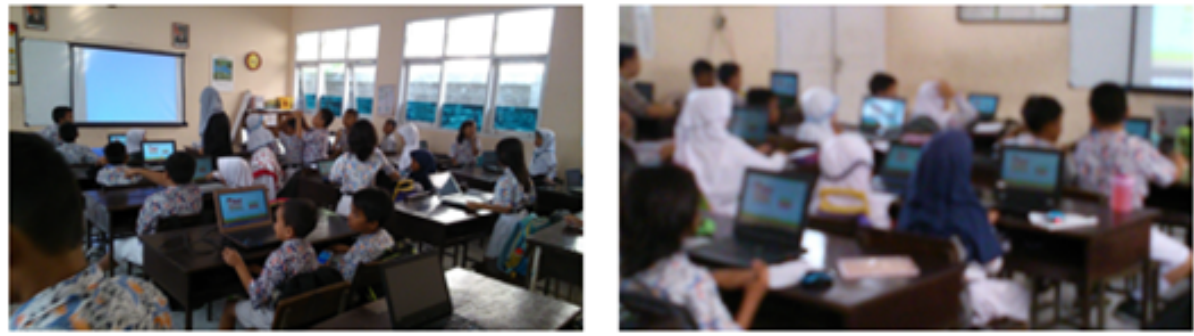

Fig. 6. 6a. and 6b. Students learn about numeracy by using game-based multimedia

Student learning activities are influenced by various factors, such as: strategies, learning models, media, teaching materials used by teachers, learning environments, and facilities in schools. Student learning activities are the basic elements that determine the success of the learning process. Good learning activities, making students able to understand the subject matter well too [16]. Student learning activities are an important element so that students' material understanding increases and causes good student learning outcomes. Student learning activities can be known from the results of observations in class. In this study student learning activities are observed when the learning process calculates horizontal ways using multimedia games. The results of observations on student activities in this study are presented in Table 4.

Table 4. Student learning activities in horizontal numeracy by using games multimedia

\begin{tabular}{|c|l|c|}
\hline No & \multicolumn{1}{|c|}{ Student Learning Activities } & $(\mathbf{\% )}$ \\
\hline 1 & Students pay attention to apperception, explanation of media usage, and learning motivation & $85 \%$ \\
\hline 2 & Students are eager to start multimedia & $85 \%$ \\
\hline 3 & Students diligently work on the pre test & $87 \%$ \\
\hline 4 & Students are busy starting games in multimedia & $88 \%$ \\
\hline 5 & Students learn material in multimedia step by step & $85 \%$ \\
\hline 6 & Students carefully work on practice questions & $88 \%$ \\
\hline 7 & Students ask the teacher when there are difficulties in learning material in multimedia & $40 \%$ \\
\hline 8 & Students look happy when completing the game stage & $85 \%$ \\
\hline 9 & Students work on each assignment & $88 \%$ \\
\hline 10 & Students work on post-test at the end of multimedia & $85 \%$ \\
\hline & Average & $\mathbf{8 1 , 8 \%}$ \\
\hline
\end{tabular}

Table 4, shows that students' learning activities in paying attention to apperception and explanations of multimedia usage from teachers and their learning motivation are $85 \%$, high. This means that students are motivated to learn and are prepared to learn to count horizontally using multimedia games. Apperception and motivation are important parts that can improve student learning activities. In apperception activities include reminding students about the material that has been given and linking it to the material to be taught. This apperception activity is intended to find out whether students understand the previous material. In this study the previous material was the introduction of numbers. This is done so that students can easily absorb the material to be learned in class. 
The material provided in this multimedia is horizontal counting. Students are observed paying attention to the apperception of the teacher seriously. So, the function of apperception in learning is to associate what material students already know with what material to learn. In addition, with the existence of apperception, it is expected that the learning process becomes more active and can improve student learning activities. According to [17] Apperception as one of the activities in learning should not be ignored because it contributes to the realization of effective learning. Motivation is a very important aspect in raising students' enthusiasm and learning activities. Therefore, so that students' learning motivation increases, teachers must be able to show the importance of experience and subject matter to students. Thus, students will understand that learning is not just to obtain value, but must be a desire to fulfill their needs in obtaining satisfactory results. This is in accordance with the opinion of [18] that learning motivation can stimulate student learning enthusiasm, whereas a lack of student learning motivation will weaken students' enthusiasm. This will also affect student learning outcomes. From the Table 4, it is also seen that the learning activities of students in starting learning with multimedia games on horizontal counting methods obtained a percentage of $85 \%$. This value is also high, meaning that students in general are passionate about starting learning to count horizontally with multimedia games. This shows that enthusiastic students learn to count horizontally using multimedia games. This score also shows that multimedia games cause students to be curious to immediately learn numbers and operations in a horizontal way, while playing games.

From the results of the observation also obtained an illustration that students were diligent in working on the pre-test on multimedia games with a percentage of $87 \%$. This score shows that carrying out the test / test that students usually do not like, becomes favored by students, because students work on the test through multimedia games. Students' activity in starting the game in numeracy multimedia scores $88 \%$. This means that students are motivated to open multimedia and play games in multimedia. Thus the use of multimedia in numeracy learning is one of the drivers for students to learn passionately. From the results of observations in the class, it was also seen that students learned material in multimedia step by step according to the stages of the game they were doing. The percentage of students who study the material sequentially is $85 \%$ or high category. This value shows that they learn numerical material they are passionate and obedient to the stages provided in multimedia. Likewise in working on practice questions, they perform the stages of the game regularly, do the tasks provided in multimedia, work on the post-test with the percentage of student activities ranging from $85-88 \%$. So all the stages they are doing are in a high position. This means that they use multimedia spiritually and are motivated to learn to count horizontally very well. So they followed all the steps of the game from beginning to end. Based on all observations on the activities of students in learning to count horizontally with multimedia games, it was obtained an illustration that student learning activities increased compared to before. 


\section{Conclusion}

Based on the research results, it can be concluded that by learning to count in the horizontal method using game-based multimedia, the ability of elementary school students to understand numeracy is seen to be increasing. Adding, subtracting, multiplying, and dividing numbers for students is no longer difficult. In addition to being able to understand the numeracy concept, the students are also happy and motivated because they can learn the horizontal method materials while playing the game. They also look livelier and actively involve themselves throughout the learning processes when they are using game-based multimedia to learn the horizontal method. To sum up, the game-based multimedia for horizontal numeracy learning is an alternative learning media that can be used by teachers to help students learn more easily and pleasantly.

\section{Refferences}

[1] N. Yue, "Computer multimedia assisted English vocabulary teaching courseware," Int. J. Emerg. Technol. Learn., vol. 12, no. 12, pp. 67-78, 2017. https://doi.org/10.3991/ijet. v12i12.7955

[2] X. Xu, "Study on effective using of multimedia teaching system and enhancing teaching effect," Int. J. Emerg. Technol. Learn., vol. 12, no. 6, pp. 187-195, 2017. https://doi.org/ 10.3991/ijet.v12i06.7093

[3] Munir, W. Setiawan, E. P. Nugroho, J. Kusnendar, and A. P. Wibawa, "The effectiveness of Multimedia in Education for Special Education (MESE) to improve reading ability and memorizing for children with intellectual disability," Int. J. Emerg. Technol. Learn., vol. 13, no. 8, pp. 254-263, 2018. https://doi.org/10.3991/ijet.v13i08.8291

[4] Munir, Konsep \& Aplikasi dalam Pendidikan Penulis Tahun Penerbit ISBN : Alfabeta, 2012.

[5] Munir, "The use of multimedia learning resource sharing (MLRS) in developing sharing knowledge at schools," Int. J. Multimed. Ubiquitous Eng., vol. 10, no. 9, pp. 61-68, 2015. https://doi.org/10.14257/ijmue.2015.10.9.07

[6] N. Fauzia, D. Rohendi, and L. S. Riza, "Implementation of the Cellular Automata Algorithm for Developing an Educational Game," pp. 169-174, 2016. https://doi.org/10. 1109/icsitech.2016.7852628

[7] C. Crawford, "The Art of Computer Game Design (eletronic version)," no. 22, 2011.

[8] Y. Wang, A. Qi, and F. Cui, "Application of the multimedia teaching system based on realtime shooting and production in martial art course," Int. J. Emerg. Technol. Learn., vol. 11, no. 3, pp. 37-41, 2016. https://doi.org/10.3991/ijet.v11i03.5347

[9] "Curriculum for Education Unit Level. Ministry of National Education of Indonesia".

[10] A. Buaud, H. Svensson, D. Archambault, and D. Burger, "Multimedia Games for Visually Impaired Children," pp. 173-180, 2007. https://doi.org/10.1007/3-540-45491-8 38

[11] W. Wiana, M. Syaom Barliana, and A. A. Riyanto, "The effectiveness of using interactive multimedia based on motion graphic in concept mastering enhancement and fashion designing skill in digital format," Int. J. Emerg. Technol. Learn., vol. 13, no. 2, pp. 4-20, 2018. https://doi.org/10.3991/ijet.v13i02.7830

[12] I. I. I. Sd, M. Media, and P. Utang, "Efforts To Improve Calculated Skills Of The 3rd Class School Students Through The Game Media ‘Utang', pp. 402-414. 
[13] Goenawan, "The Learning of METRIS Arithmetics, More Easily and Quickly', Jakarta:Atma Jaya University.," p. 2013, 2013.

[14] C. Hursen and C. Bas, "Use of Gamification Applications in Science Education," Int. J. Emerg. Technol. Learn., 2019.

[15] B. Niu, F. Wang, and A. Qi, "Construction of maker multimedia technology for the course of sports marketing," Int. J. Emerg. Technol. Learn., vol. 12, no. 9, pp. 85-94, 2017. https://doi.org/10.3991/ijet.v12i09.7488

[16] Erniwati. 2015. Efforts to Increase Historical Learning Activities of Students Through Cooperative Learning Learning Type Snowball Throwing in Class XI IPS 3 SMA 1 Pasaman. Indonesian Education Journal, 1 (1): 1-12.

[17] Mariska, Kurniawan, E. S \& Fatmaryanti, S. D. 2013. The Effectiveness of Apperception and Motivation in Increasing Students' Understanding of Concepts in the Subject of SMP Negeri 13 Purworejo. Radiation, 3 (2): 160-165.

[18] Mariska, Kurniawan, E. S \& Fatmaryanti, S. D. 2013. The Effectiveness of Perception and Motivation in Increasing Students' Understanding of Concepts in the Subject of SMP Negeri 13 Purworejo. Radiation, 3 (2): 160-165.

\section{Author}

Dedi Rohendi is currently an associate professor at the Department of Mechanical Engineering Education, Faculty of Technology and Vocational Education. He is also a lecturer in post graduated program of Technical and Vocational Education Study Program at Universitas Pendidikan Indonesia (UPI). He completed a master degree in Computer and Information Technology from Universitas Gadjah Mada, Yogyakarta, Indonesia, in 2000 and his Doctoral degree in Mathematics Education from Universitas Pendidikan Indonesia, Indonesia in 2009. He has published some mathematics education papers especially in using multimedia in teaching and learning mathematics, computer education, and inovation media in some international journals also in IOP Conference Series and Atlantis Press.

Article submitted 2019-04-16. Resubmitted 2019-06-08. Final acceptance 2019-06-08. Final version published as submitted by the authors. 